\section{STRICTURE OF THE URETHRA; OLD KIDNEY DISEASE; DEATH.}

\author{
To the Elitor of THE LANCET.
}

SIR,-Without wishing to enter into the controversy between Mr. Holt and Mr. Henry Smith respecting the unfortunate case in the latter gentleman's practice, I should be glad to record a case having a direct bearing upon the question at issue.

W. $\mathrm{N}$ - applied among the out-patients at Westminster Hospital on Friday, October 14th, 1864, bringing with him a bottle of his urine, apparently containing pus. On going into his history it was evident that he was suffering from stricture; I therefore attempted to introduce a catheter, but found the stricture to be very tight. With some trouble, however, I got in a No. 2 catheter, and drew off a considerable quantity of clear urine.

I heard nothing more of the patient till midday on Monday, the 17th, when a relative came to beg me to see him at his own house. It appeared that on getting home on the Friday he had a rigor, and soon after began to vomit bilious matter, which had continued up to that time. His friends applied on the Saturday to the house-surgeon at Westminster, who sent him a dose of opium; but as he did not improve, they called in a neighbouring practitioner, who gave him two pills, each containing one grain of opium, and effervescing mixture, and declared that the blaclder was empty, though the patient had passed no urine since the catheter was used. I found him much exhausted, with herpes around the mouth and a quick pulse. The bladder being evidently full, I passed a No. 2 catheter with some difficulty, and drew off a large quantity of elear urine. Ordered brandy and soda-water, to check the vomiting.

At ten P.Mr. I was again summoned, and found that the man had decidedly lost ground since the morning. As the vomiting still continued and the bowels were constipated, I ordered ten grains of compound colocynth pill, and a magnesian draught in the morning; to continue the brandy and sodawater. Urine was drawn off by the catheter, which was kept in, so that the friends might draw off the water when required.

October 18th.-The vomiting had ceased, but the bowels had not been moved. Patient in a semi-comatose condition; pulse feeble and fluttering. Ordered half an ounce of brandy erery hour. Died at three P.M.

On post-mortem examination I found the bladder fully distended, although the friends cleclared that the urine was drawn off regularly up to the last. The ureters were greatly enlarged, but the kidneys much contracted, the pelves being, however, much enlarged, so that not more than a third of the secreting structure of the organs was left. The pubes, with the urethra and bladder, were carefully removed, when I found a very tight stricture of the bulbous portion of the urethra, with one false passage beneath the mucous membrane, entering the canal again furtlier back. The liver was healthy.

This case resembles in very many particulars that recorded by Mr. Smith, with the exception that death followed the simple introduction of the catheter. Supposing that the patient had been an inmate of the hospital, and that, undeterred by the occurrence of a rigor, I had dilated the stricture, this case might have been recorded as one of "death rapidly following the use of Holt's dilator." In my case the patient undoubtedly died of old kidney disease, which was aggravated and brought to a climax by the simple introduction of a catheter; and Mr. Smith's case would in all probability have been shown to be of a similar nature had the kidneys been extracted, as they might easily have been, through the perineum.

I believe I am correct in saying that one of the three fatal cases mentioned by Mr. Smith as having occurred in King's College Hospital was a casual case of stricture, which the then house-surgeon (some years back) split up in the surgery proprio motu, and sent away without any after-treatment; but this can hardly be considered a fair specimen of the operation.

$$
\text { I am, Sir, your obedient servant, }
$$$$
\text { CHRISTOPHER HEATH, F.R.C.S. }
$$

Cavendish-place, March 28th, 1865.

\section{ON THE TREATMENT OF PNEUMONIA. To the Editor of THE LANCE'T.}

SIR,-As no other person has replied to the paper which Dr. Hughes Bennett has very recently contributed to your valuable journal, will you allow me to question the valiaity of the arguments he has adduced in favour of a restorative treatment of this disease. Not that I should now have ventured to dispute the justness of the views of so eminent a physician as Dr. Bennett, did I not think that the best method of curing so important a complaint as pneumonia is a subject of great interest to all practical men, particularly at a time when the opinions of the profession are in many respects so divided as to the relative value of the stimulating, restorative, and antiphlogistic treatment of disease.

The chief fact which Dr. Bennett endeavours to prove from the statistics he has brought forward on the subject is, "that a simple primary pneumonia, whether single or double, if treated by the restorative plan, is not a fatal disease. Surely 105 cases, of which twenty-six were double, are sufficient to establish this proposition;"- -and the whole purport of the paper is to demonstrate the superiority of restorative over depleting measures in the treatment of inflammation of the lungs. Now, in the first place is "simple primary pneumonia" fairly and completely represented by the class of cases from which Dr. Bennett has derived his statistics? or, in other words, can the 125 cases admitted into the Royal Infirmary of Edinburgh be considered a good average illustration of pneumonia in general, or of that class of cases in the commencement of which it has hitherto been thought advisable to employ antiphlogistic remedies? I believe not. Many of the cases received into hospitals have advanced beyond that stage when antiphlogistic treatment would be of any avail, whilst others have had their system so weakened by want, intemperate habits, or previous disease as to render restorative means imperatively necessary. Nor does the fact that "several of the cases were those of healthy, vigorous young labourers" in any way lessen the force of my objection, inasmuch as those kind of patients do not bear depletion so well as some may suppose. Strength and development of muscle are not incompatible with a comparatively weak state of the vascular system, a poor state of the blood, and an impaired condition of the whole constitution, particularly in men whose quantity of food is often the very minimum required by the amount of labour im. posed upon them, and whose health has been, perhaps, further deteriorated by intemperance. For these reasons it is evident that the plan of treatment which would ill suit the poorly-fed and hard-worked labourer might be well adapted for the plethoric, sanguine, and highly-fed gentleman, who enjoys his beef-steak at breakfast, or otherwise indulges his appetite with all that a good digestion can dispose of.

Then, again, the statistics in question by no means show that the treatment employed in the 105 cases of simple pneumonia was really a "restorative" one. For, of these 105 cases "there were nine bled by venesection and subject to an antiphlogistic treatment before or immediately upon admission;" that is to say, nearly nine per cent. had been bled \&c. before other means were adopted*-nine per cent. of that class of patients to whose peculiar condition and circumstances $I$ have just adverted, and many of whom are admitted to have been "weak and broken-down sempstresses." Nor, by the way, do these nine cases appear" to liave progressed so badly, for "1 case recovered in 7 days, 2 in 14 days, 1 in 16 days, 1 in 17 days, 1 in 20 days," \&c. "Therefore, when in connexion with the above considerations we bear in mind that even the most strenuous supporters of the antiphlogistic treatment do not employ this method in all cases of pneumonia, nor throughout the whole course of the disease; and when we also bear in mind that Dr. Bennett himself does not object to "small bleedings to the extent of eight or twelve ounces" for the sake of relieving " engorgement of the lung," nor to the exhibition of small doses of tartar-emetic, I cannot help thinking that his "restorative plan" of curing pneumonia differs very little froin that which would be adopted in a similar class of cases by those practitioners who practise the usual method of treatment.

That 125 cases out of 129 should hare recovered is highly creditable to Dr. Bennett's skill and good management, and

* "The amount of blood extracted varied from twelve to thirtr-six ounces the latter in two bleedings." 